\title{
سبل تعزيز سيادة القانون بشكل أفضل من وجهة نظر الفقه الإسلامي
}

\author{
Doi: $10.23918 /$ ilic2020.43 \\ د. استامة إبراهيم علي التايه \\ باحث متفرغ أكاديمية العاصمة الدولية ـ الأردن ـ عمان \\ Osam6870@yahoo.com
}

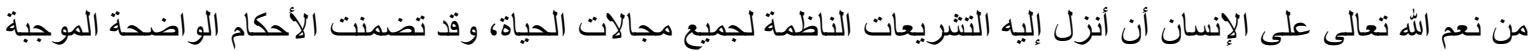

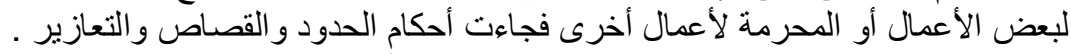

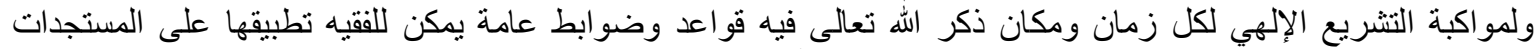

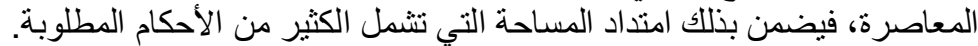

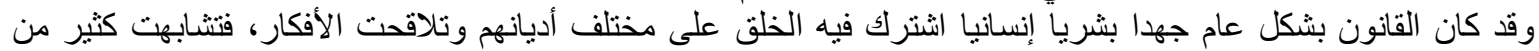

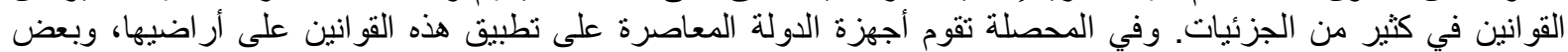

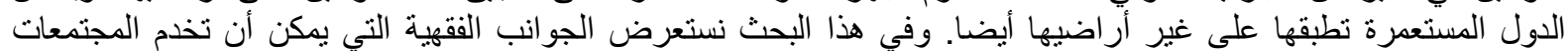

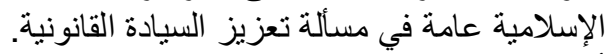

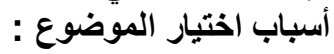

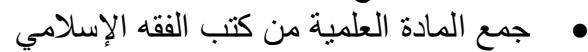

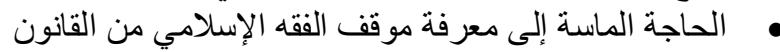

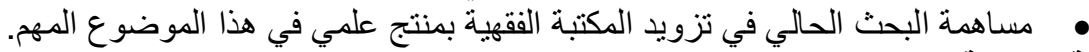

مشكلة الاراسة ( البحث)

يمكن بيان مشكلة الدر اسة في الإجابة على الأسئلة التالية:

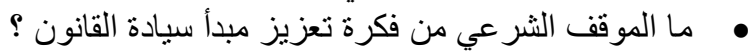

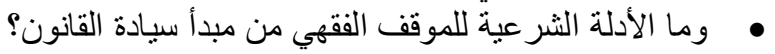

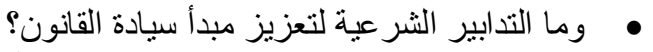

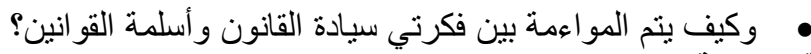

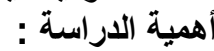

تظهر أهمية الدراسة بالنظر إلى أسباب زعزعة سيادة القوانين، وأهمية الدور التثقيفي بشكل عام والتثقيف الديني بشكل

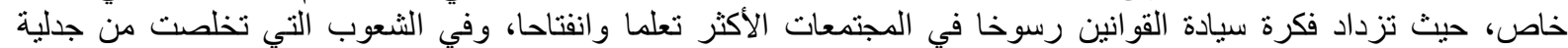

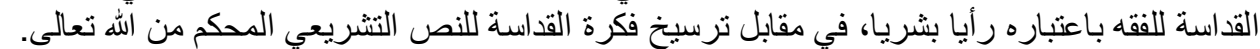

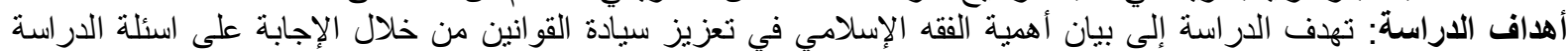

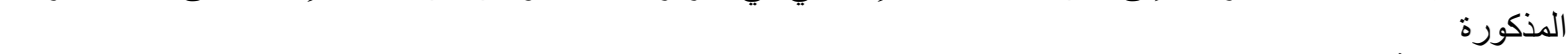
منهج الدراسة: تقوم الدراسة على المنهج الاستقر ائي التحليلي وتقدم وجهة نظر الباحث من خلال استقر اء تام للنصوص القر آنية

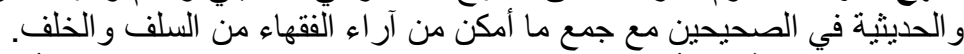

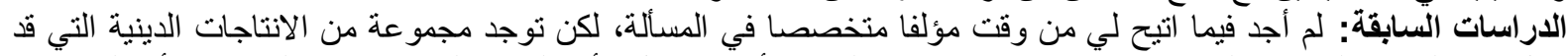

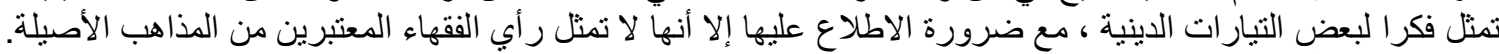

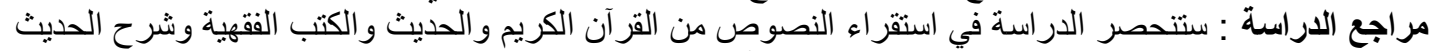
المبحث الأول : مفهوم سيادة القانون

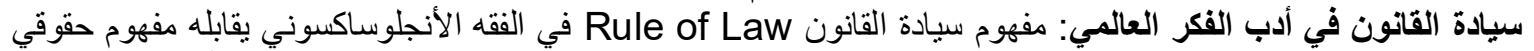

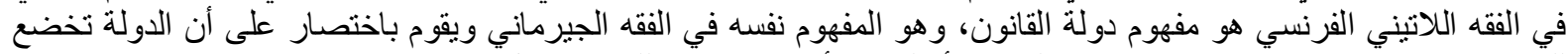

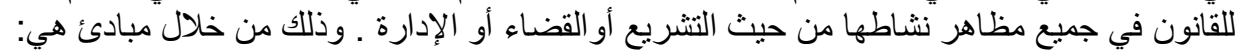

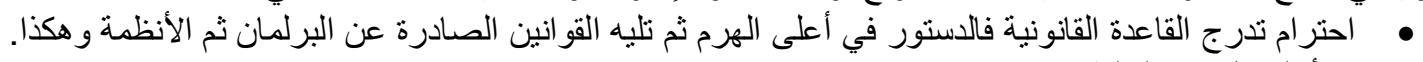

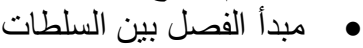

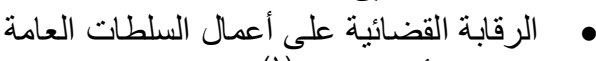

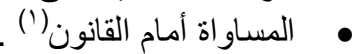

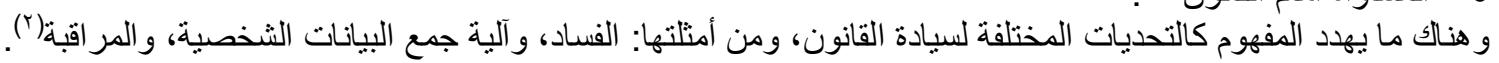

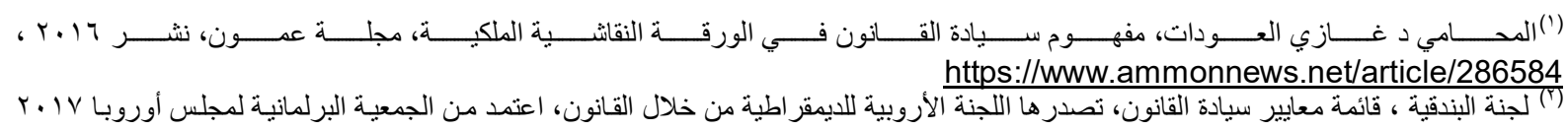




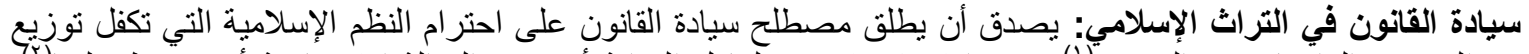

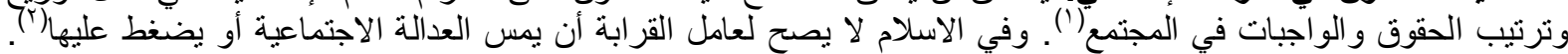

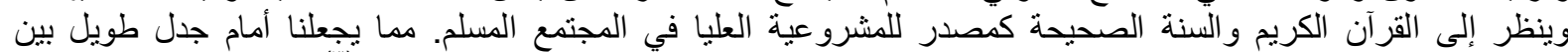

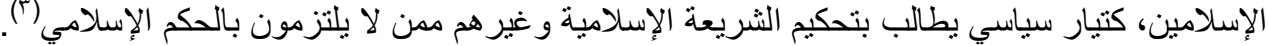

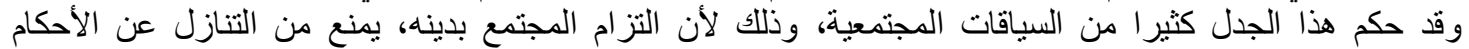

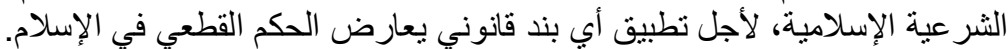

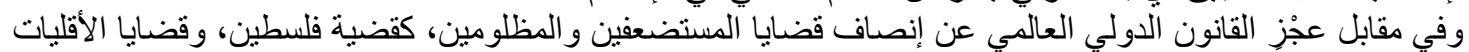

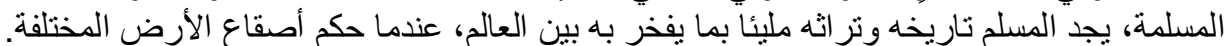

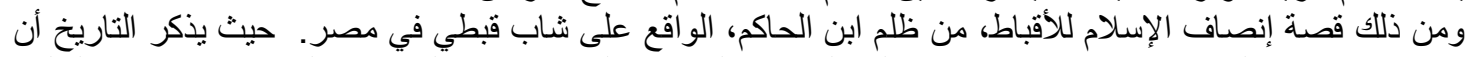

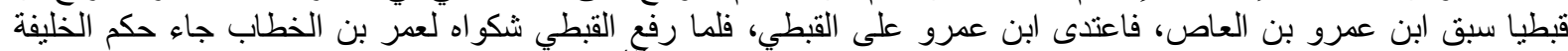

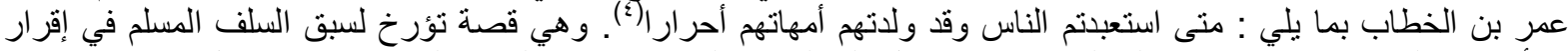

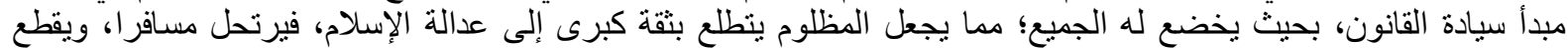
الو لايات الممتدة من أفريقيا إلى أعماق الجزيرة الجئ العربية في آسيا.

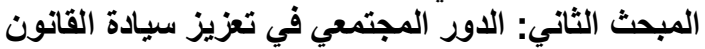

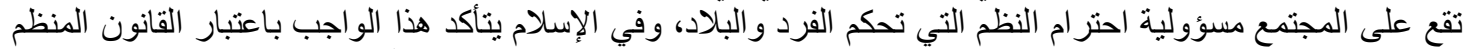

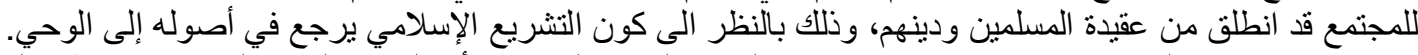

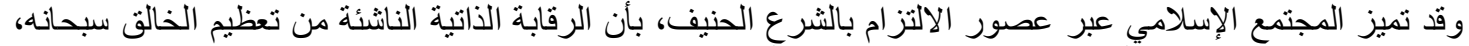

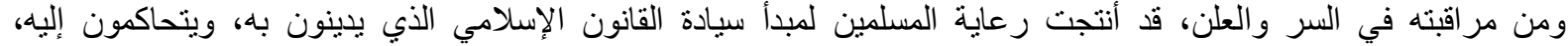
ويسبرون في حياتهم على نهجنه

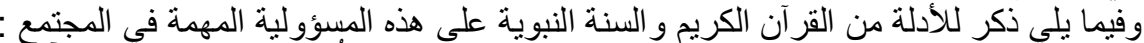

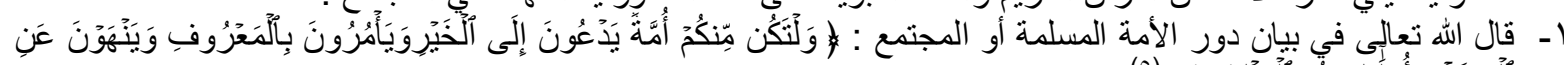

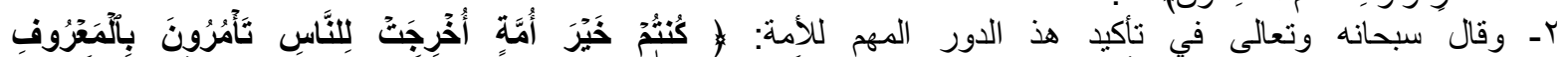

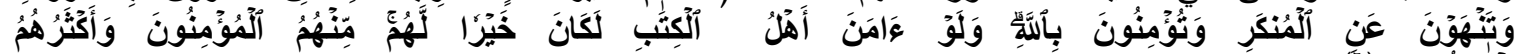

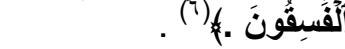

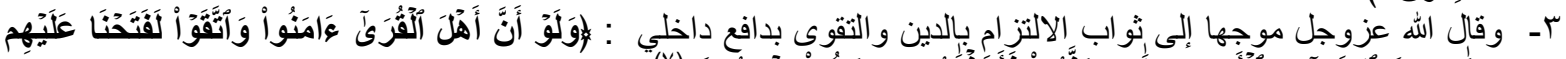

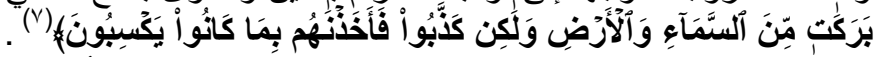

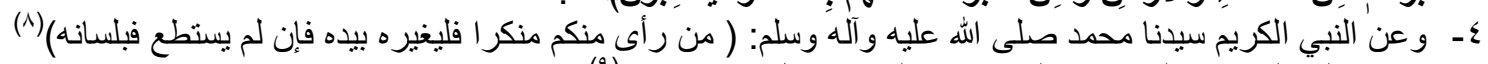

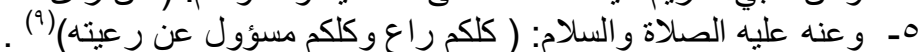

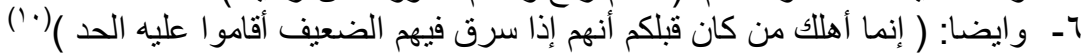

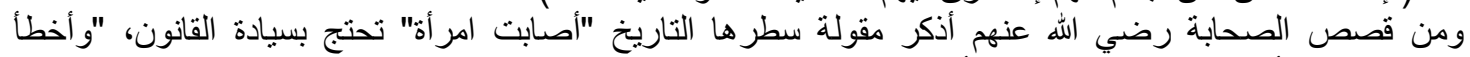

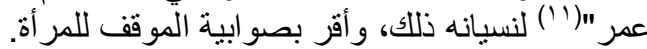
و هذه النصوص الثر عية الثابتة، تظهر مكانة التشريعات الإسلامية الناظمة للمجتمع -و هي التي تقابل القانون- وذللك بما يمثل السيادة و المرجعية العليا، وتجعل الجميع تحت هذا القئة القانون الحق.

(') دعبد الكريم بكار ، مقال بعنوان ونبلوكم بالثر والخير فتنة ، مجلة البيان تصدر عن المنتدى الإسلامي العدد ع^ ص م

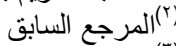

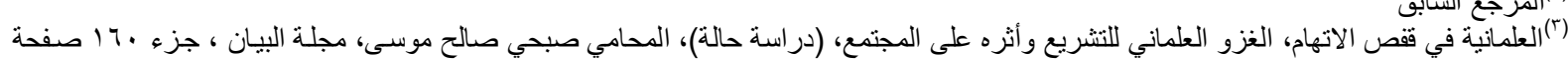

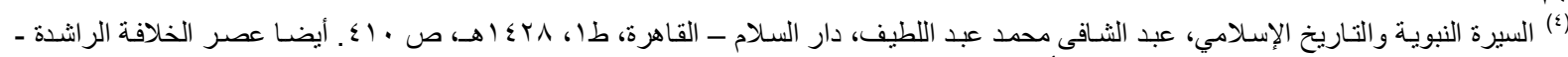

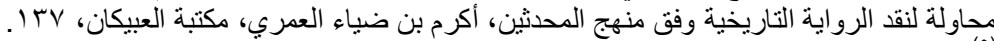

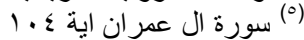

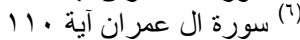

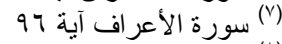

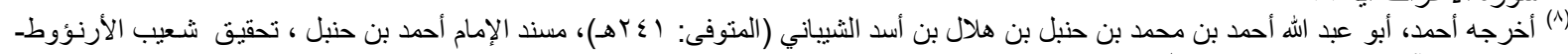

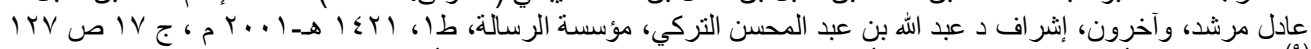

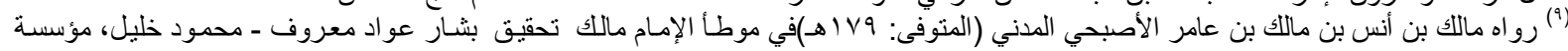

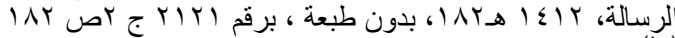

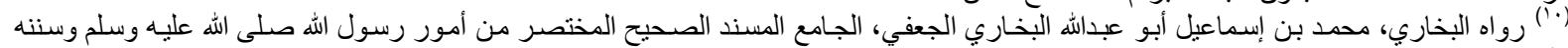

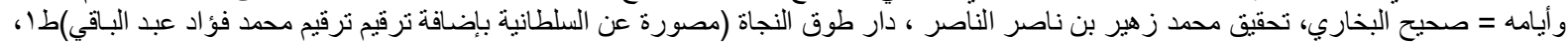

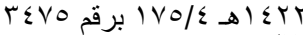

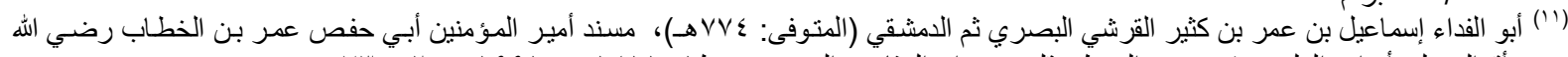

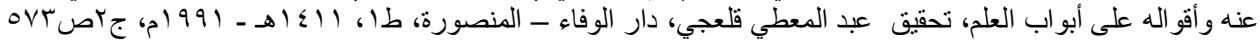




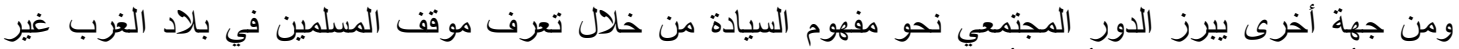

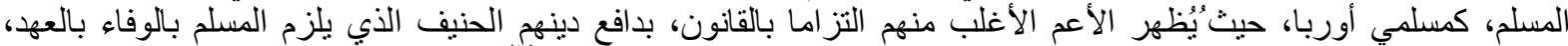

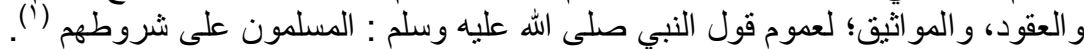

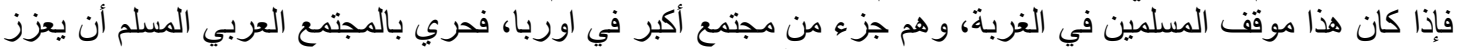

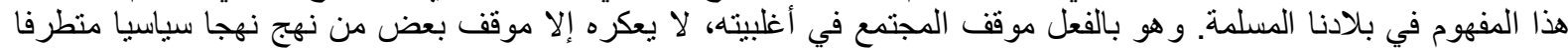

المبحث الثالث: دور المؤسسات الاينية في تعزيز سيادة القانون يخالف الإسلام وروحهـ.

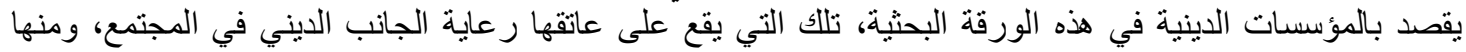

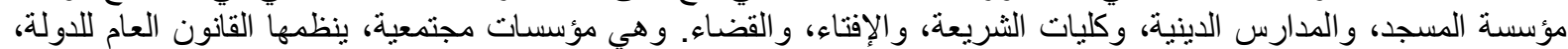

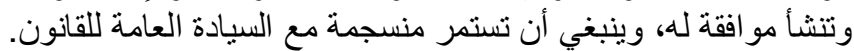

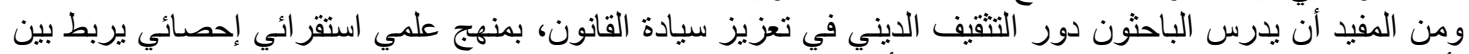

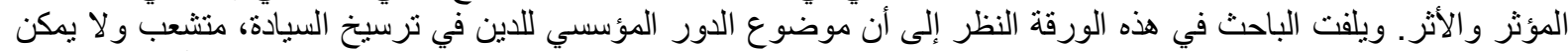

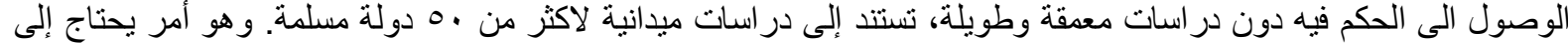

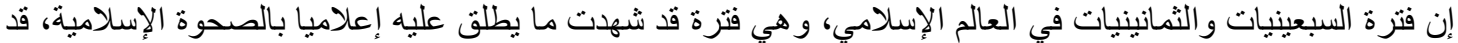
فريق عمل كبير.

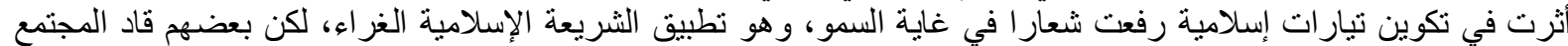

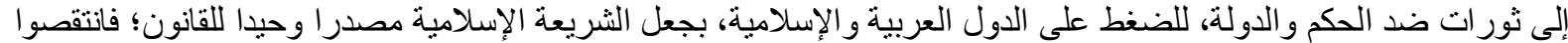

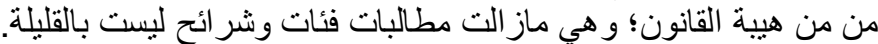

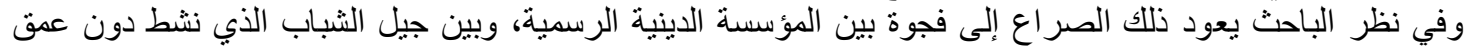

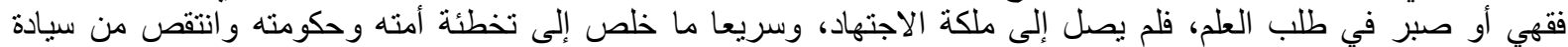

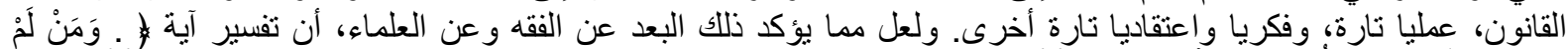

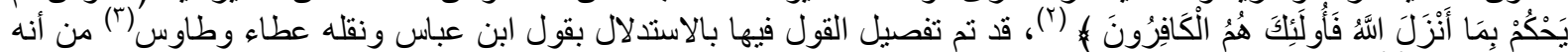

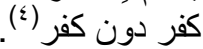

ويمكن تحسين دور المؤسسة الدينية في مجال تعزيز السيادة من خلال ما يلي من إجر اءات مهمة:

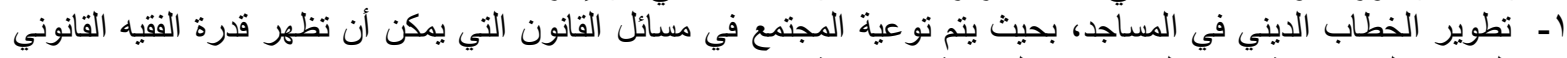

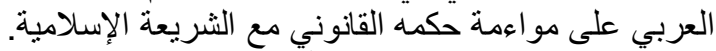

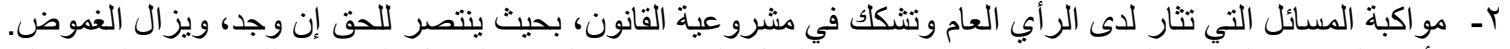

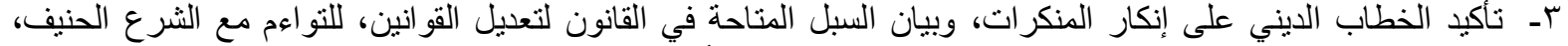

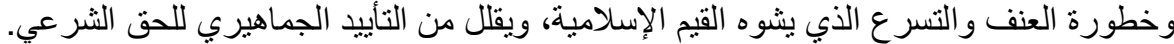

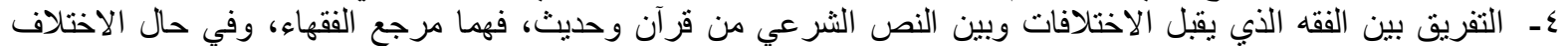

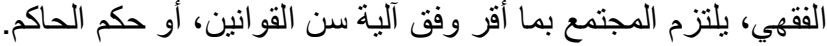

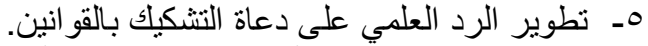

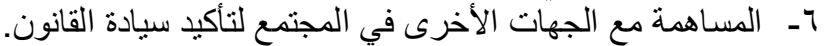

المبحث الرابع: منطلبات الفقه الإسلامي لتعزيز مبلأ سيادة القانون

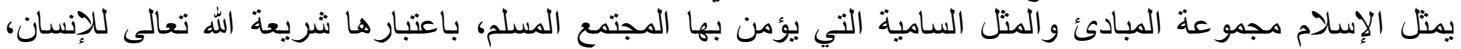

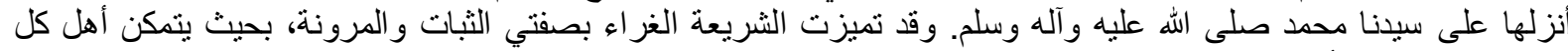

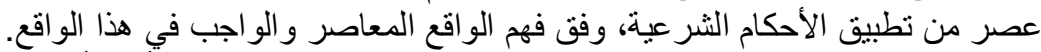

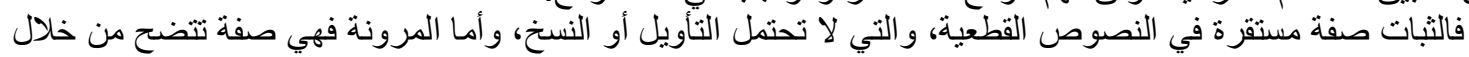

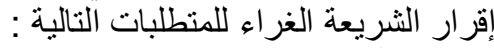
1- 1 - مبدأ الاجتهاد التشريعي.

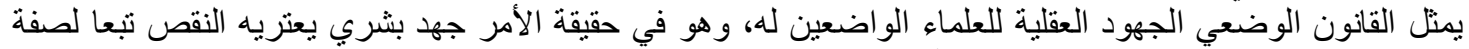
العقل البشري الذي يتصف بالقدرات التفكيرية التي أودعها الله تعالى فيه، كما يتصف بالهدئ الهدودية وهي صفة تؤكد غياب الكثير من الحقائق عنه.

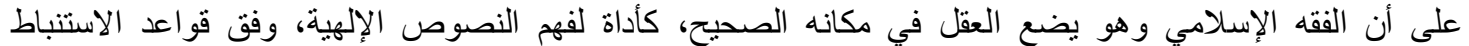

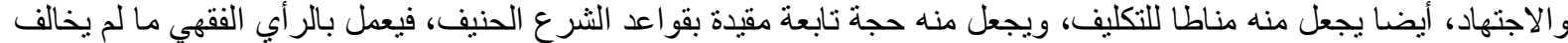
النص القر آني أو الحديث الصحيح الصريح.

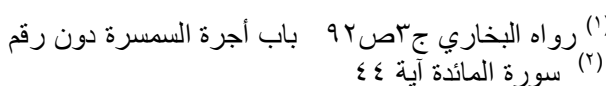

$$
\begin{aligned}
& \text { (") الثوري، أبو عبد اله سفيان بن سعيد بن مسروق الثوري الكوفي (المنوفى: (17(هـ): تفسير الثوري، دار الكتب العلمية، بيروت ـ لبنان }
\end{aligned}
$$

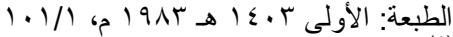




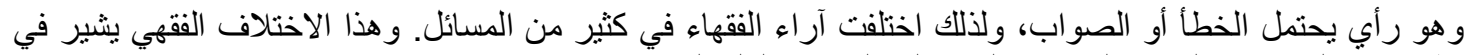
جانب التخطئة منه، إلى حقيقة النقص البشري، الفقير إلى الوحي والعلم اليقابني.

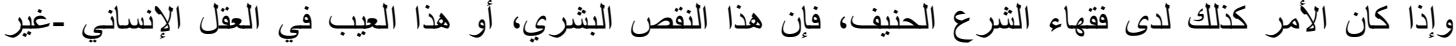

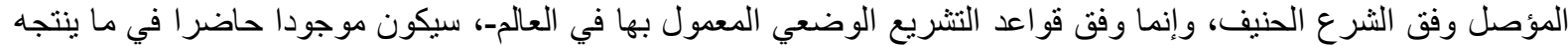
من تشريعات وضعية.

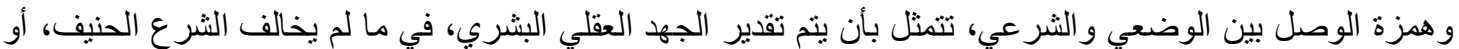

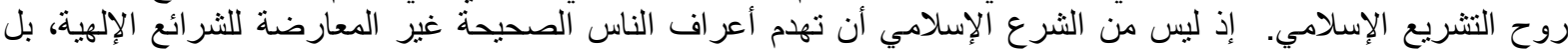

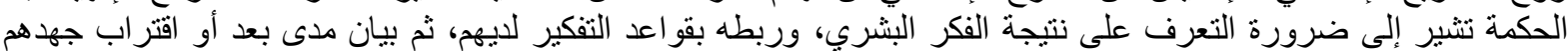

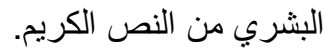
إن ذصوص النص الثريعة الإسلامية المتمنلة بالقرآن الكريم والسنة المطهرة، قد تضمنت مبدأ الاجتهاد التشريعي، و هذا يتيح

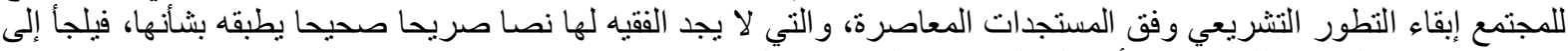

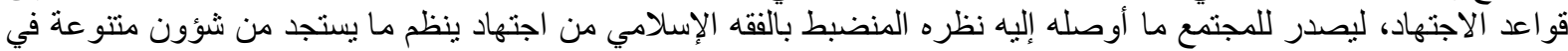

وقد جاءت النصوص الثرعية المؤصلة للاجتهاد كما يلي :

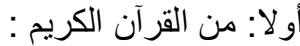

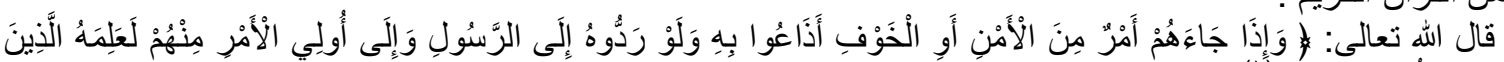

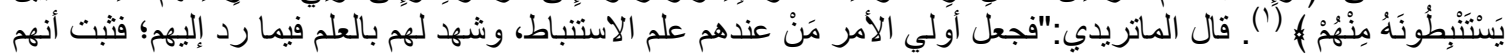

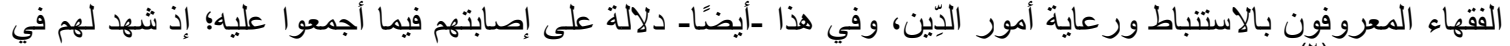

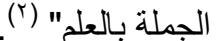

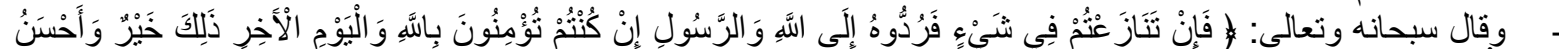

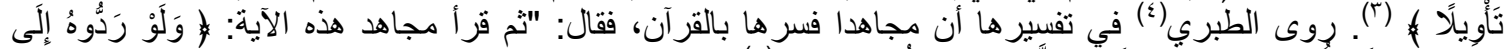

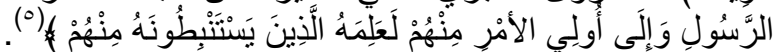

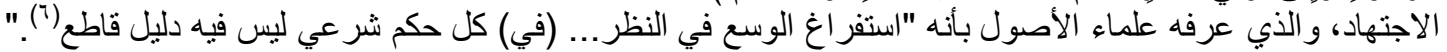
ثنانيا: من السنة المطهرة

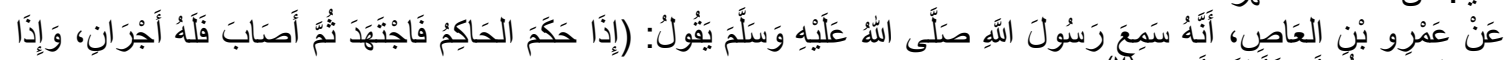

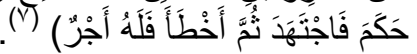

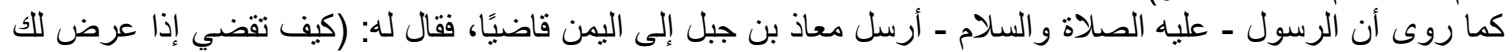

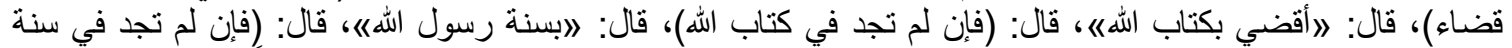

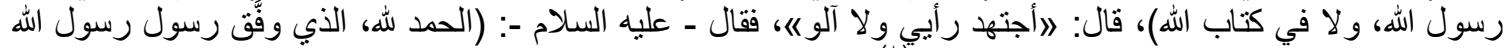

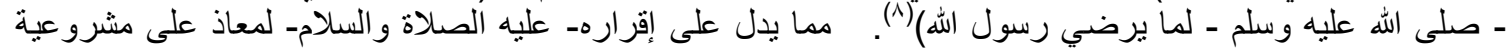

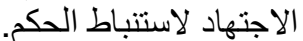

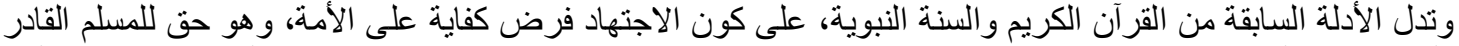

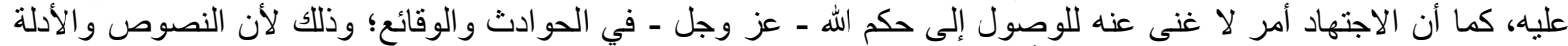

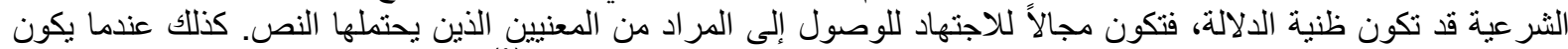

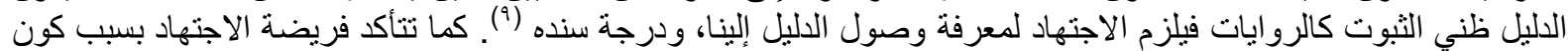

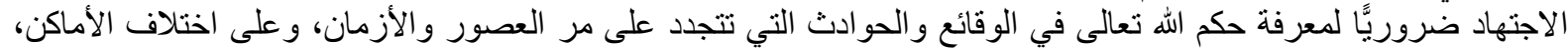

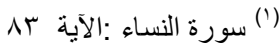

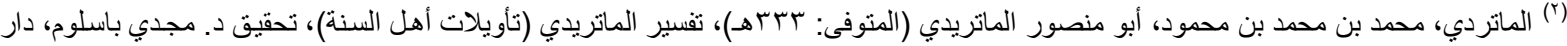

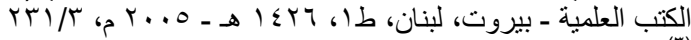
هو

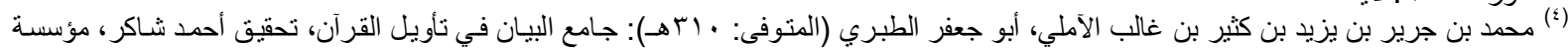

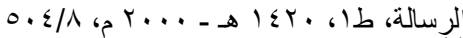

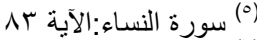

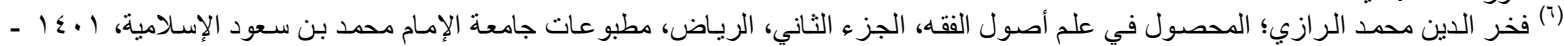

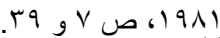

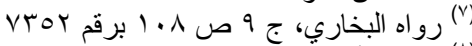

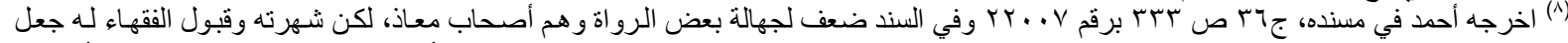

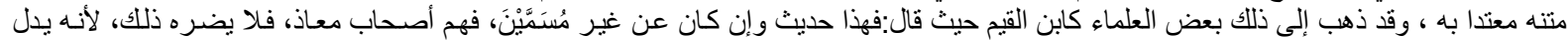

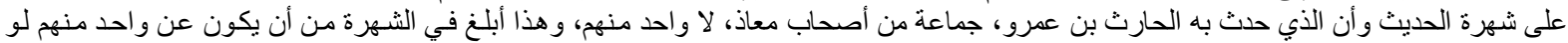

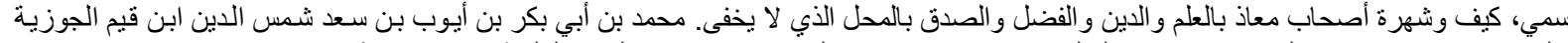

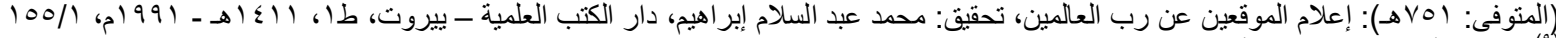

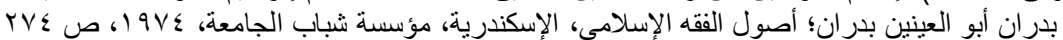


و التي لا سبيل لحصر ها. وللاجتهاد شر ائط يجب ان تتفور في المجتهد تؤوهله للنظر و الاستنباط كالاسلام و العدالة و العلم بالكتاب

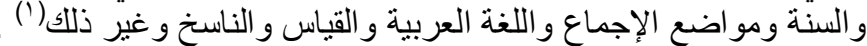

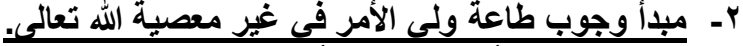

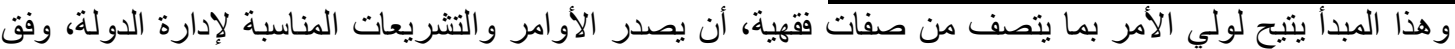

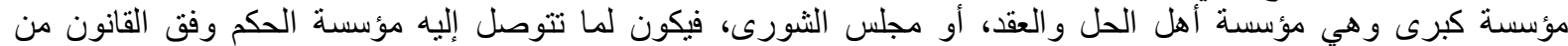

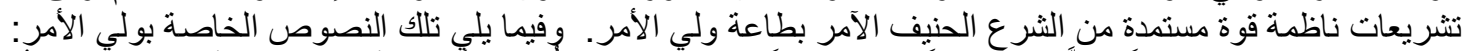

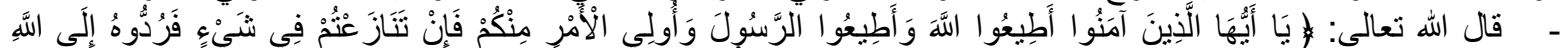

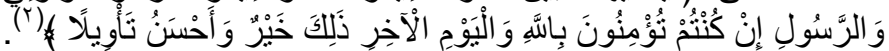

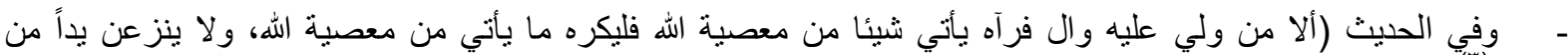

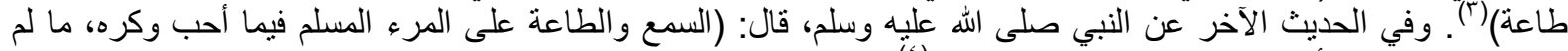

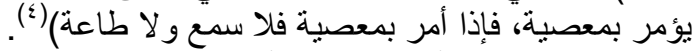
r-علدم إنكار تغير الأحكام بتغير الأزمان

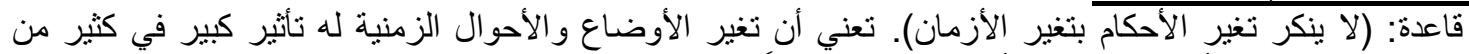

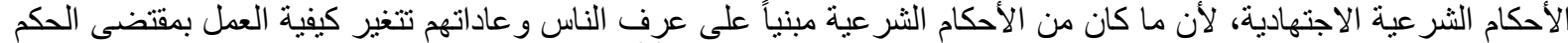

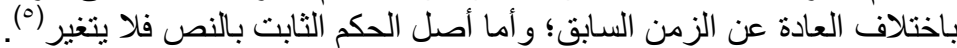

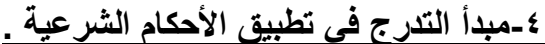

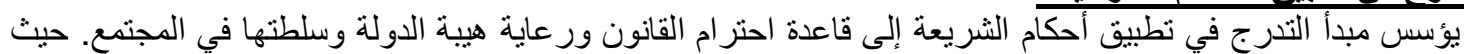

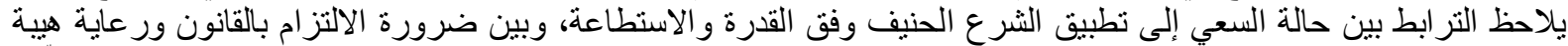

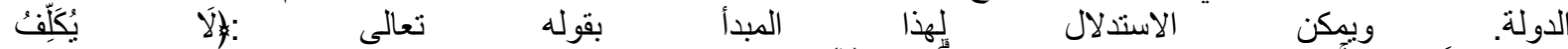

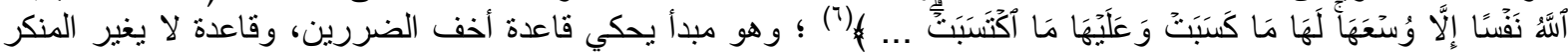

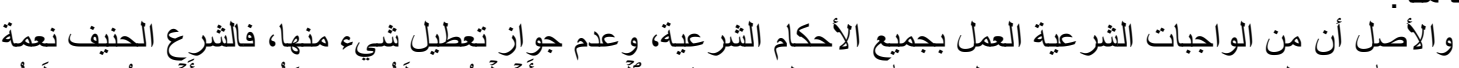

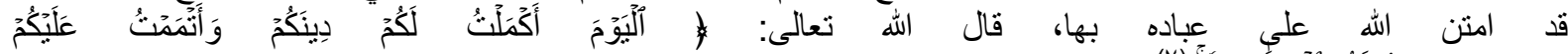

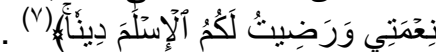

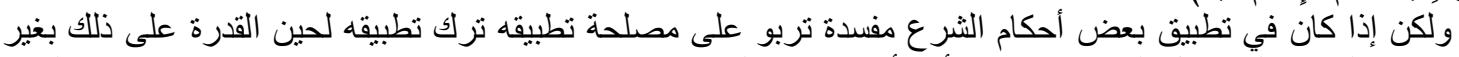

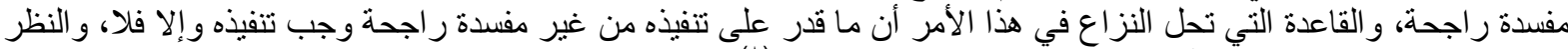

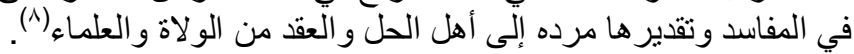

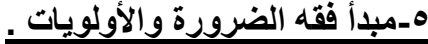

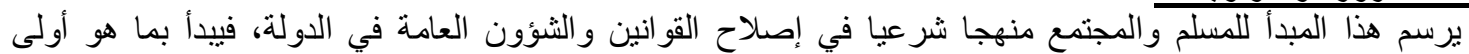

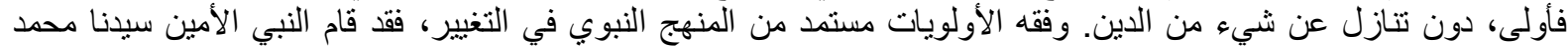

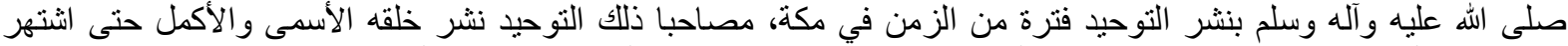

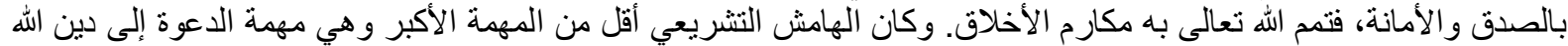
تعالى ونبذ الثرك و الكفر.

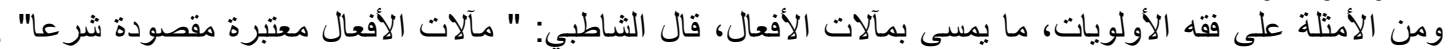

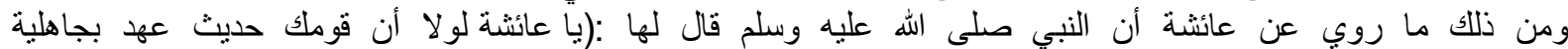

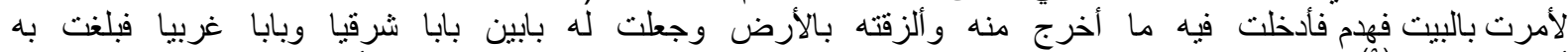

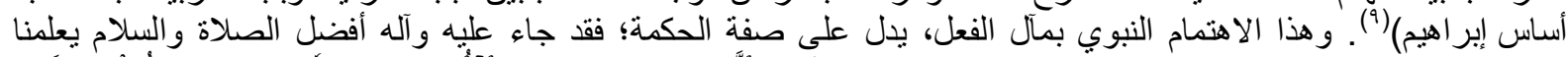

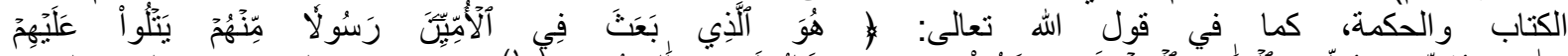

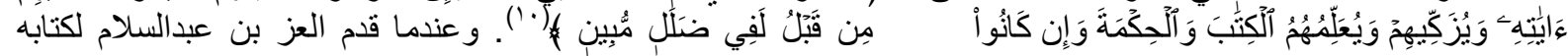

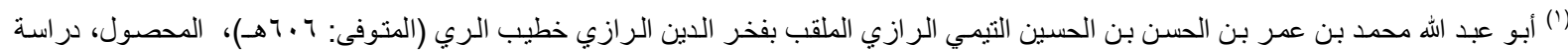

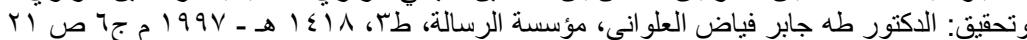
(r)

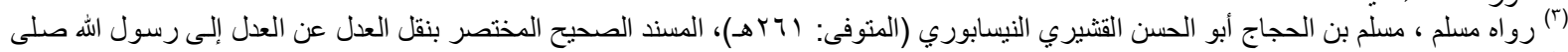

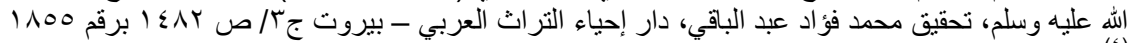

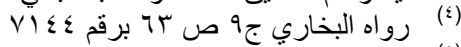

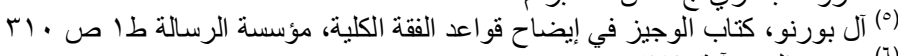

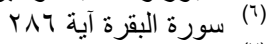

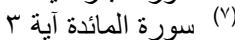
https://www.islamweb.net/ar/fatwa/163027/

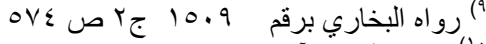

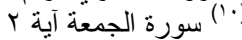




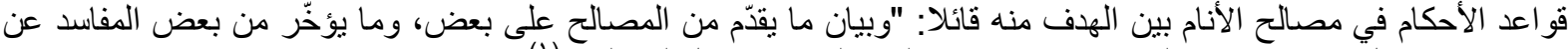

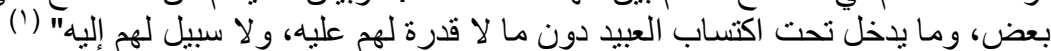

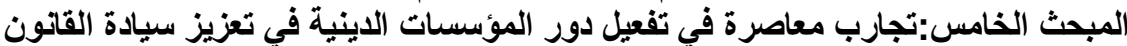

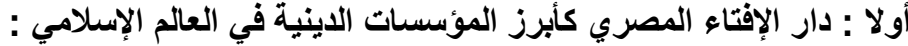

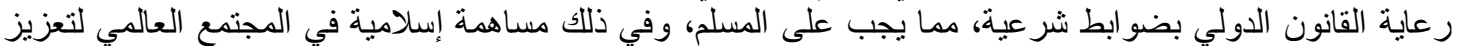

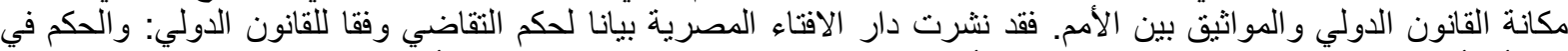

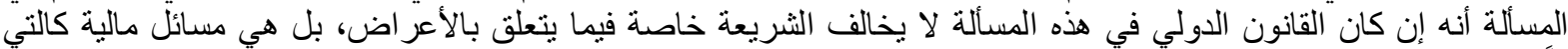

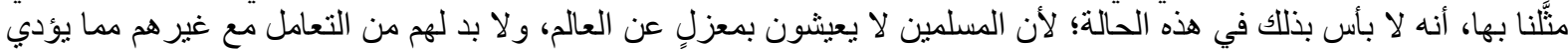

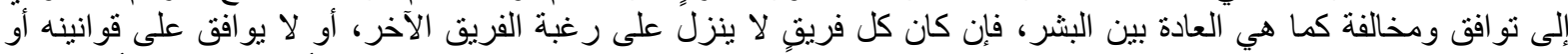

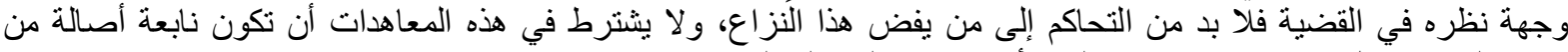

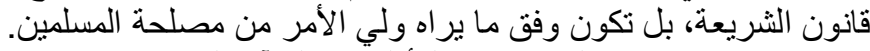

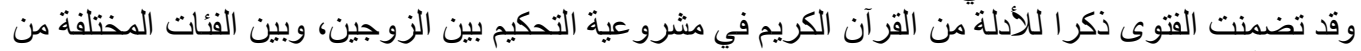

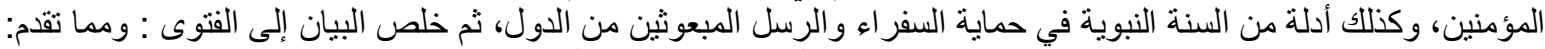

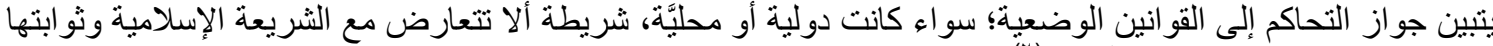

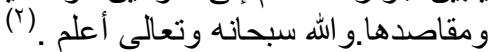
ثانيا: افتاء مشيخة الأزهر الثريف : بين شيخ الأزهر في تصريح له موقف الأزهر من المحكمة الدستورية، بقوله : شيخ

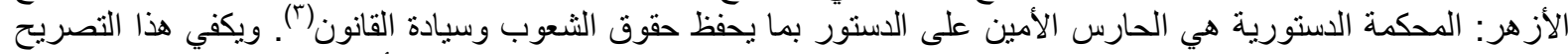

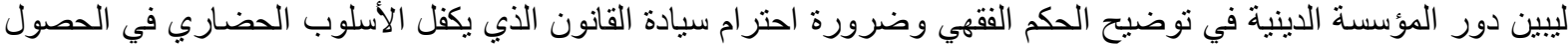

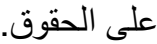

ثالثا: في لقاء علمي في دولة الإمارات العربية المتحدة:

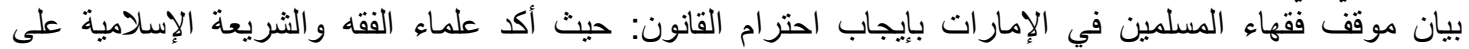

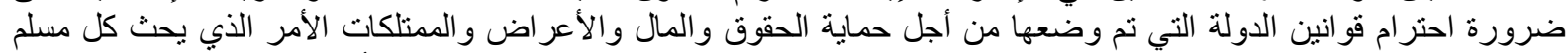

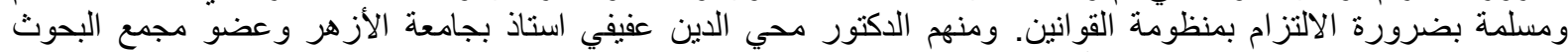

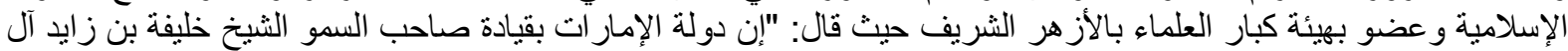

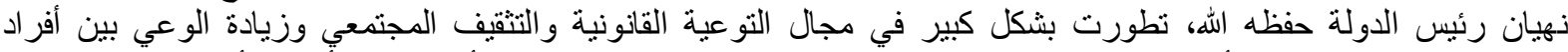

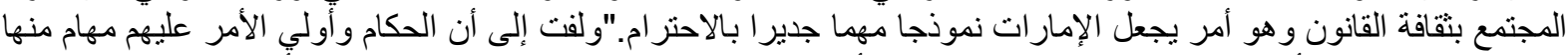

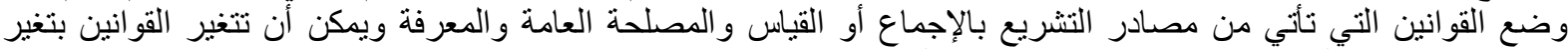

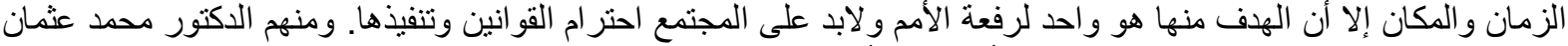

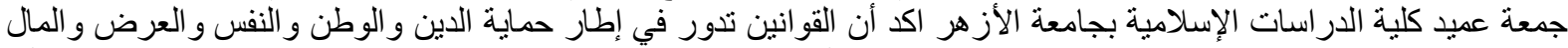

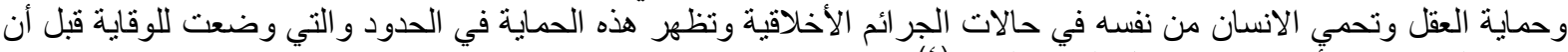

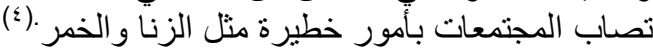

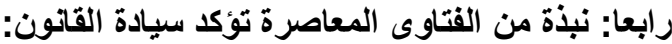

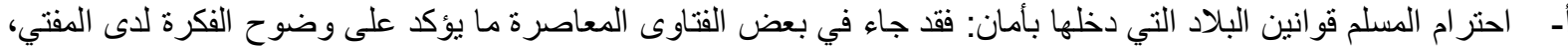

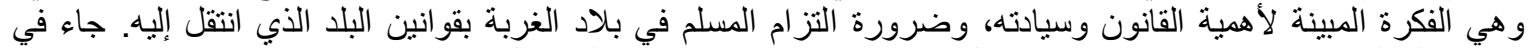

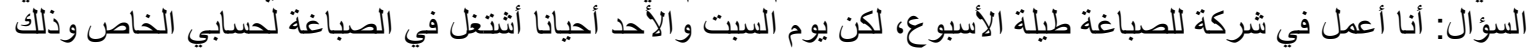

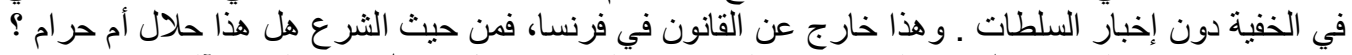

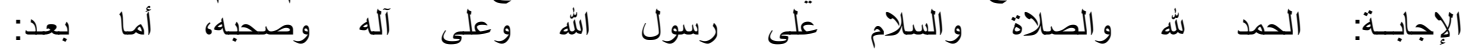

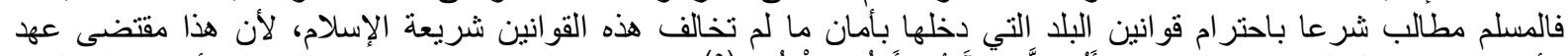

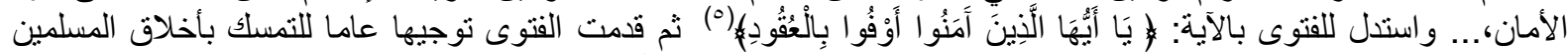

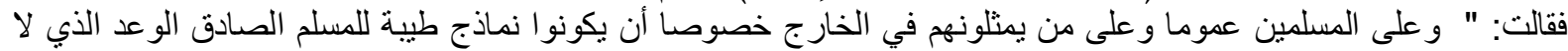

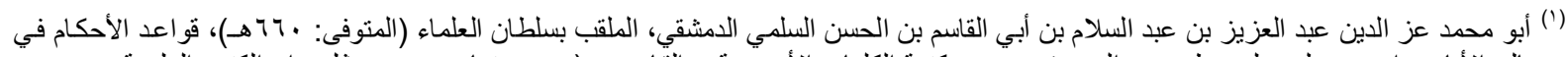

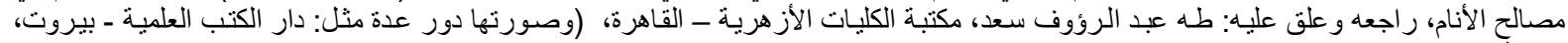

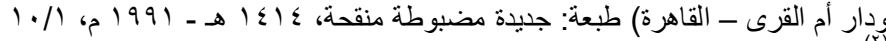
https://www.dar- موقة alifta.org/ar/ViewFatwa.aspx?ID=14134\&LangID=1\&MuftiType=0\&\%D8\%A7\%D9\%84\%D8\%AA\%D8\%AD\% D8\%A7\%D9\%83\%D9\%85 \%D8\%A5\%D9\%84\%D9\%89 \%D8\%A7\%D9\%84\%D9\%82\%D9\%88\%D8\%A7\%D 9\%86\%D9\%8A\%D9\%86 \%D8\%A7\%D9\%84\%D9\%88\%D8\%B6\%D8\%B9\%D9\%8A\%D8\%A9 \%D8\%A7\%D 9\%84\%D8\%AF\%D9\%88\%D9\%84\%D9\%8A\%D8\%A9 http://www.azhar.eg/m-alazhar/sheikh-alazhar/ArtMID/775/ArticlelD/30028 (")

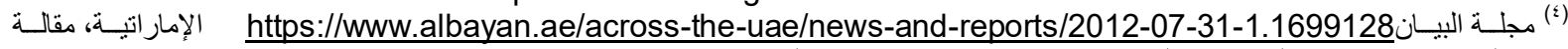

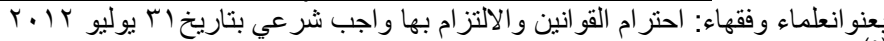

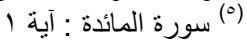




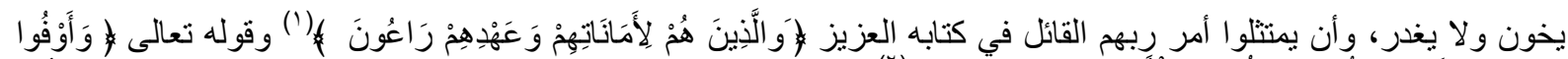

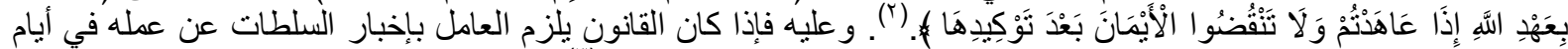

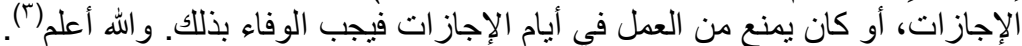

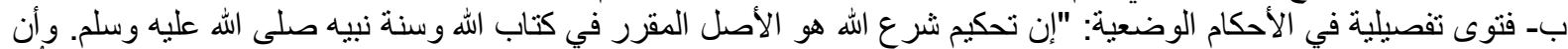

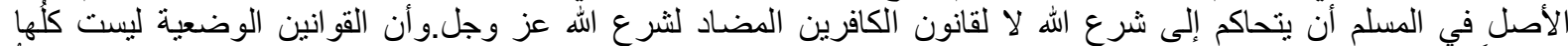

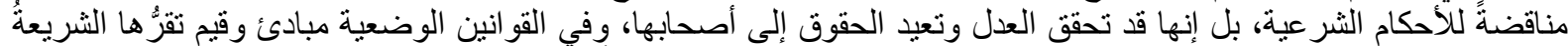

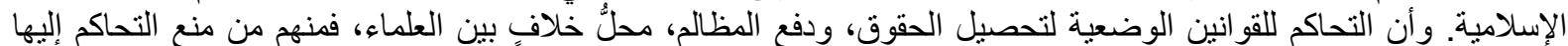

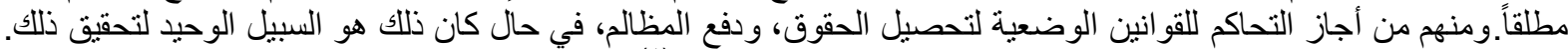

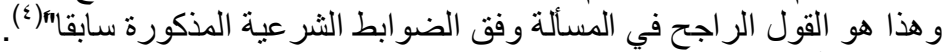

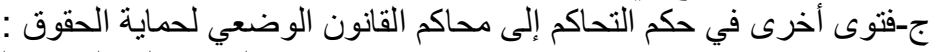

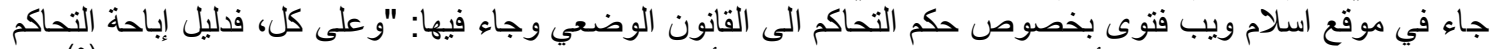

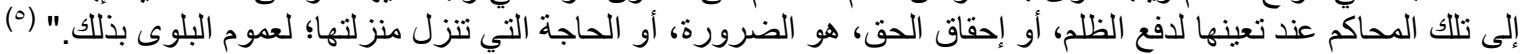

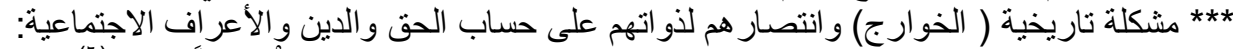

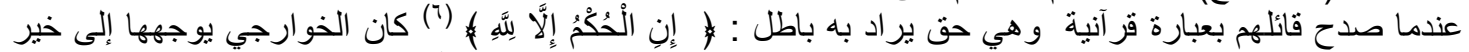

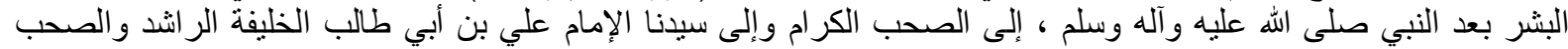

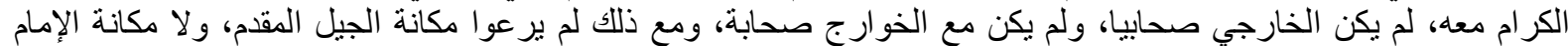

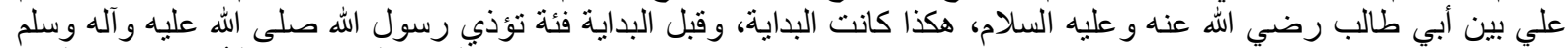

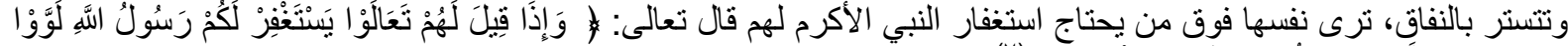

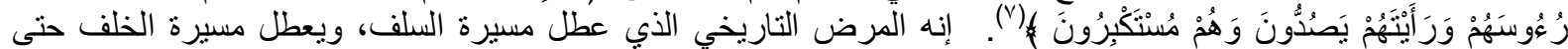

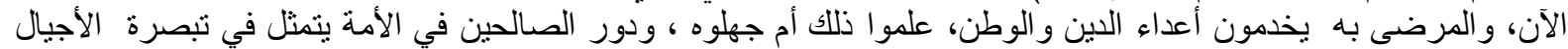

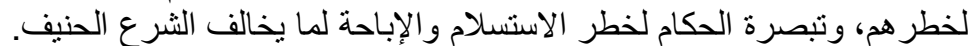
الخاتمة : النتائج والتوصيات

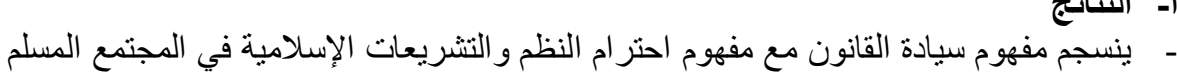

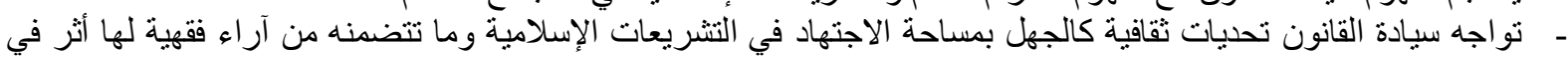
الفتوى و القضاء. ومن التحديات الثقافية قلة الوعي بنظرة الفقهاء المسلمين للعمل بالقوانين الوضعية، والوانية الوقوع في خطأ الحكم عليها حكما مطلقا دون تفصيل.

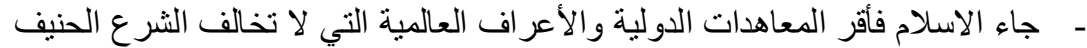

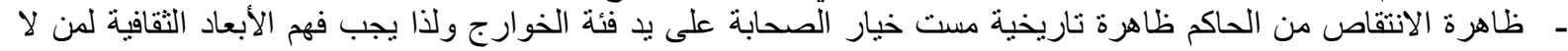

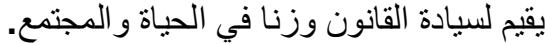
ـ ـ للافتاء ومشيخة الأزيان هي ودور الافتاء في العالم الإسلامي دور مهم في تعزيز سيادة القانون والأعراف الدولية.

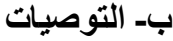
- زيادة منسوب الوعي لاتى طلبة العلوم الثر عية بفلسفة النتريعات القانونية للتعرف على نسبة المشروعية في ذلك.

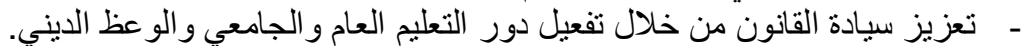

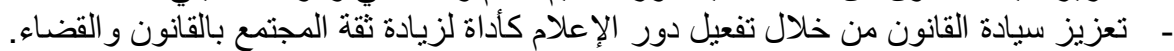

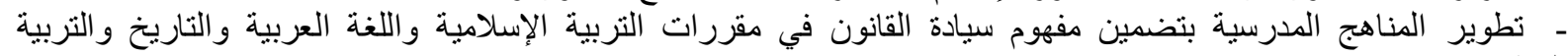
الوطنية. ـ ـ ـ مو اجهة الفكر المنحرف بدعوته للحو ار و المناظرة وكثف الثبهات لرده إلى سبل حماية الوطن ونهضته. المراجع : بحسب المؤلف الفر المبر

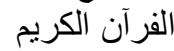

人 (r) (1) 9) https://www.islamweb.net/ar/fatwa/78859/ ${ }^{(\mathrm{r}}$ ف i http://yasaloonak.net/2019/01/\%D8\%B6\%D9\%88\%D8\%A7\%D8\%A8\%D8\%B7\%D9\%8F-كألك نو \%D8\%A7\%D9\%84\%D8\%AA\%D9\%91\%D9\%8E\%D8\%AD\%D8\%A7\%D9\%83\%D9\%85\%D9\%90\%D9\%84\%D9\%84\%D9\%82\%D9\%88\%D8\%A7\%D9\%86\%D9\%8A\%D9\%86\%D8\%A7\%D9\%84\%D9\%88\%D8\%B6\%D8\%B9\%D9\%8A\%D8\%A9-\%D9\%84/

${ }^{(5)}$ https://www.islamweb.net/ar/fatwa/236581/\%D8\%AD\%D9\%83\%D9\%85\%D8\%A7\%D9\%84\%D8\%AA\%D8\%AD\%D8\%A7\%D9\%83\%D9\%85-\%D8\%A5\%D9\%84\%D9\%89\%D8\%A7\%D9\%84\%D9\%85\%D8\%AD\%D8\%A7\%D9\%83\%D9\%85\%D8\%A7\%D9\%84\%D9\%88\%D8\%B6\%D8\%B9\%D9\%8A\%D8\%A9

OV سورة الأنعام آية (1)

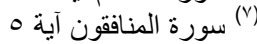


ا - الأصبحي، ماللك بن أنس بن مالك بن عامر الأصبحي المدني (المتوفى: Vو اهـ)، موطأ الإمام ماللك، تحقيق بشار عواد

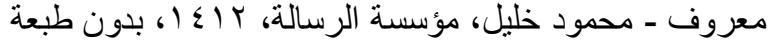

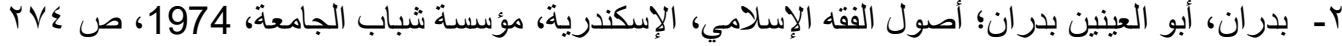

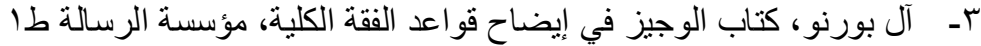

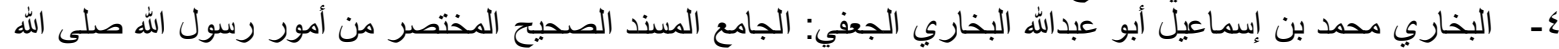

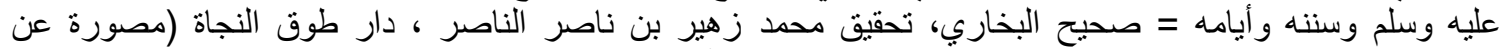

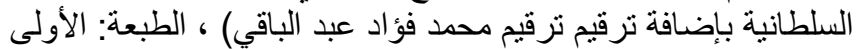

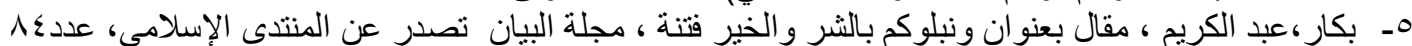

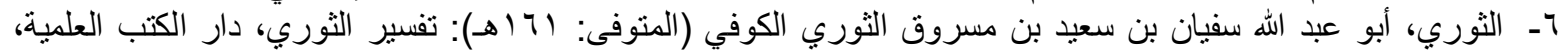

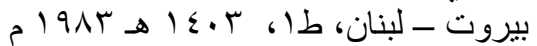

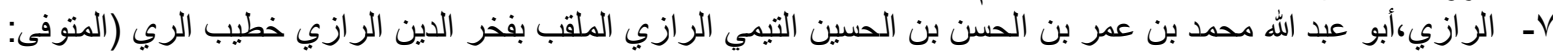

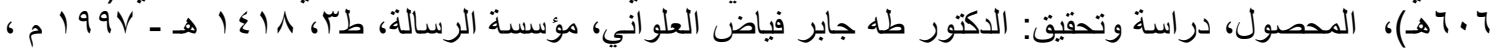

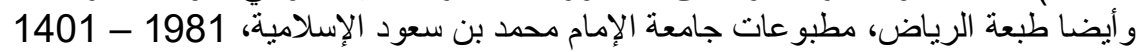

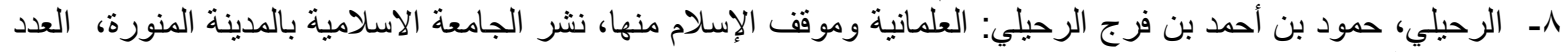

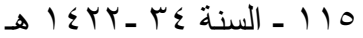

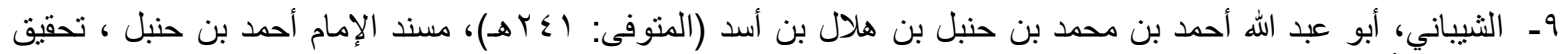

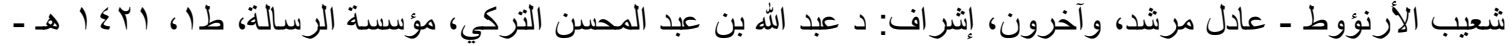
ب... • ـ الطبري، محمد بن جرير بن بزيد بن كثير بن غالب الآملي، أبو جعفر الطبري (المتوفى: · اسبهـ)، جامع البيان في تأويل

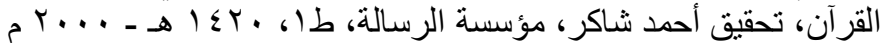

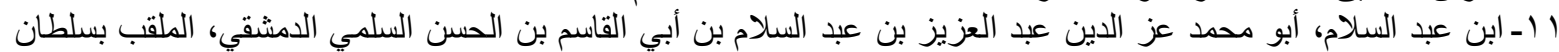

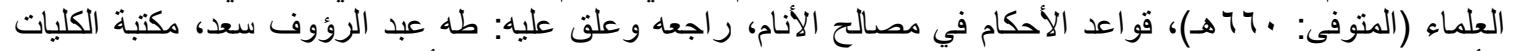

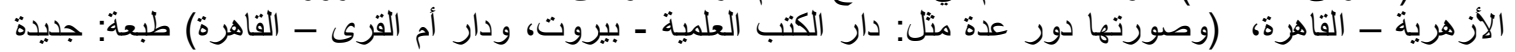

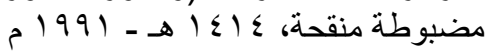

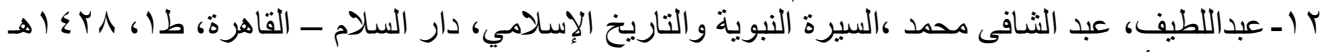

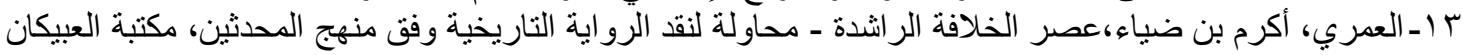

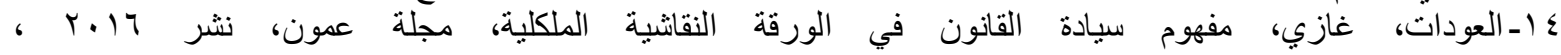
https://www.ammonnews.net/article/286584

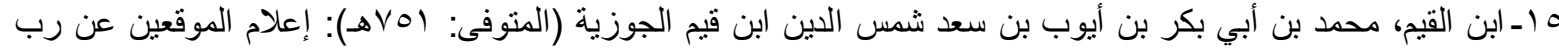

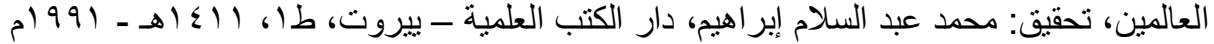

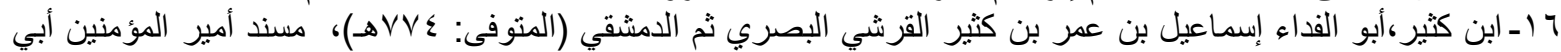

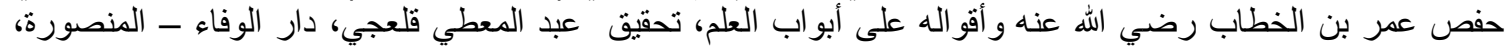

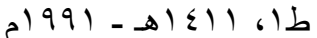
V ا ل لجنة البندقية، مجمو عة مؤلفين، قائمة معابير سيادة القانون، لجنة البندقية ، تصدر ها اللجنة الأروبية للايمقر اطية من خلال

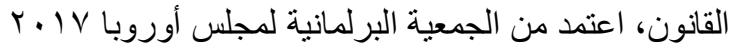

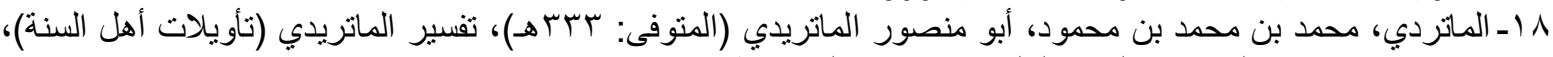

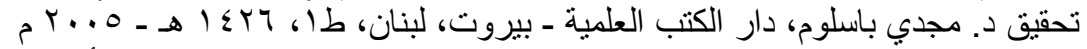

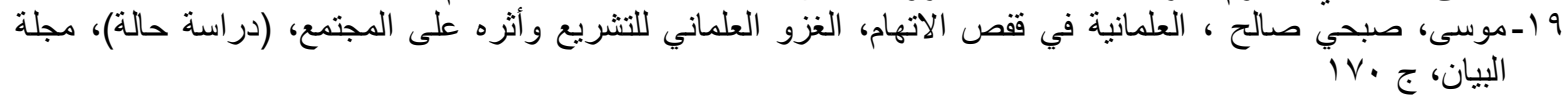

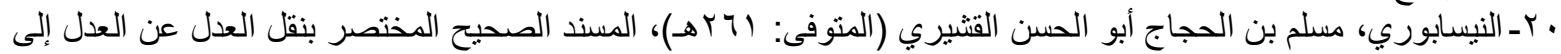

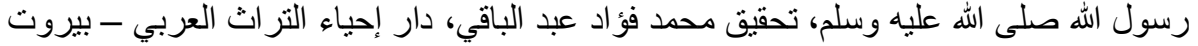

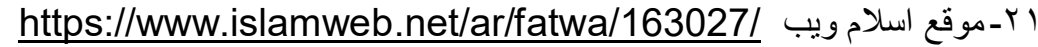
https://www.dar- موقع دار الافتاء المصرية، alifta.org/ar/ViewFatwa.aspx?ID=14134\&LangID http://www.azhar.eg/m-alazhar/sheikh- الأزريف alazhar/ArtMID/775/ArticleID/30028 ع r-مجلة البيان https://www.albayan.ae/across-the-uae/news-and-reports مقالة بعنوان علماء وفقهاء:

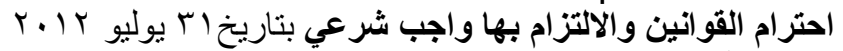

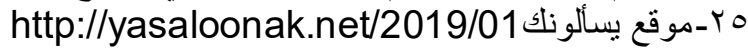
ملخص البحث

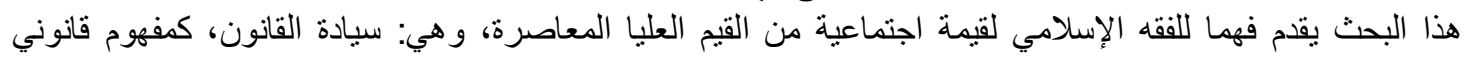

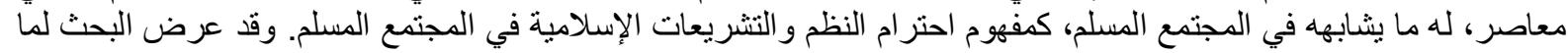




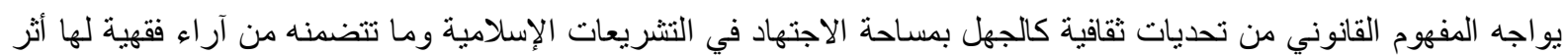

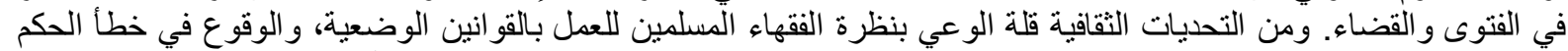

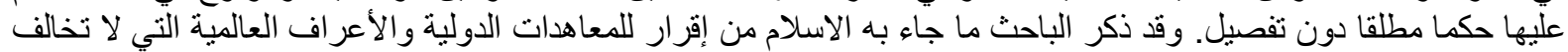

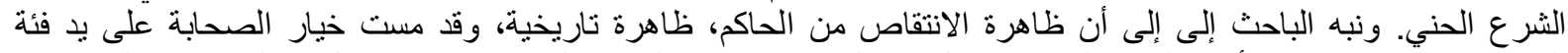

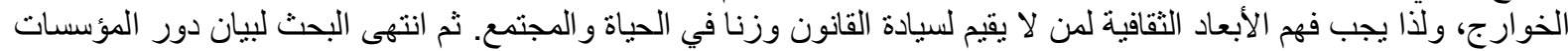

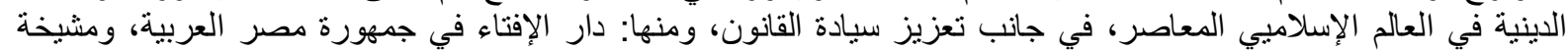
الأزهر التشريف، و وغير ها. الإنيا. وقد كانت مباحث هذا البحثث كما يلي:

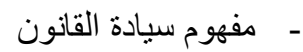
-

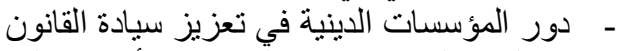

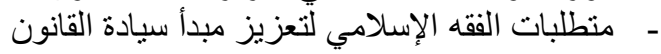

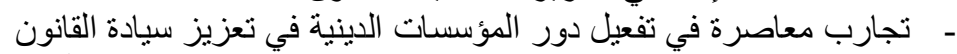

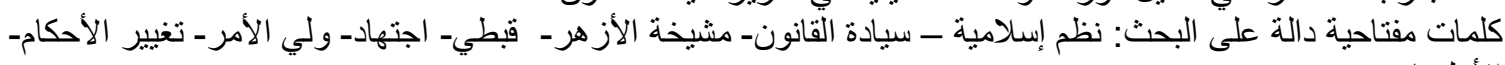

\section{Research Summary}

الأولويات.

This research provides the understanding of Islamic jurisprudence of one social value among contemporary higher values, namely: the rule of law, as a contemporary legal concept which has a similar analogy in Muslim society, as is the concept of respect for Islamic systems and legislation in Muslim society. The research presented the cultural challenges facing the legal concept, such as ignorance of the area of ijtihad in Islamic legislation and the jurisprudence it contains that have an impact on the fatwa and the judiciary. Among the cultural challenges are the lack of awareness of the view of Muslim jurists to work with statutory laws, and making the mistake of misjudging them completely, without elaborating. The researcher mentioned the approval of Islam for international treaties and international norms that do not violate the Islamic law. The researcher cautioned the phenomenon of derogation the ruler, a historical phenomenon, that touched the option of companions regrding the Kharijites, so you must understand the cultural dimensions of those who do not evaluate the rule and weight of law in life and society. Then the research reached the point to show the role of religious institutions in the contemporary Islamic world, in the aspect of strengthening the rule of law, including: Dar Al Iftaa in the Arab Republic of Egypt, the sheikh of Al-Azhar, and others.

The topics of this research were as follows:

- The concept of the rule of law

- The societal role in promoting the rule of law

- The role of religious institutions in promoting the rule of law

- Islamic jurisprudence requirements to strengthen the principle of the rule of law

- Contemporary experiences in activating the role of religious institutions in strengthening the rule of law

Keywords: Islamic systems - rule of law - Al-Azhar Sheikh - Coptic - ljtihad - guardian - change provisions - priorities. 